\title{
SEISMIC VULNERABILITY ASSESSMENT METHODOLOGY FOR HISTORICAL BUILDINGS WITH CULTURAL VALUE
}

\author{
E. ONESCU ${ }^{1 *}$, I. ONESCU $^{2}$ AND M. MOSOARCA ${ }^{2}$ \\ ${ }^{1}$ Faculty of Architecture and Urban Planning, Politehnica University of Timisoara, Romania \\ e-mail: eugen.eugen@student.upt.ro (*corresponding author) \\ ${ }^{2}$ Urban Planning and Architecture Research Center, Politehnica University of Timisoara, Romania \\ e-mail: iasmina.onescu@upt.ro, marius.mosoarca@upt.ro
}

Keywords: Historical Structure, Masonry, Cultural value, Vulnerability assessment

\begin{abstract}
Banat seismic region represents the second most important seismic area of Romania. The area is characterized by shallow earthquakes, with a peak ground acceleration ag=0,20g [1]. The city was influenced by several architectural styles, keeping until nowadays many valuable masonry historical buildings.

Most of the historical buildings present severe decay due to the lack of proper maintenance over time. Timisoara was selected to be European Capital of Culture 2021, so the buildings in the historical districts are expected to be visited by a large amount of tourists.
\end{abstract}

This paper presents the seismic vulnerability assessment of two of the most important historical urban districts of Timisoara. The evaluation is based on existing Italian vulnerability assessment methodology [2], following on-site investigation. Moreover, there is considered also the influence of the cultural value of the historical buildings. Following a set of new proposed architectural-artistic, urbanistic and social-economic factors, there was developed a new investigation form, presented and explained in the paper [1].

In the end, the authors present a detailed empirical seismic vulnerability assessment influenced by the cultural value for historical masonry buildings in Timisoara city, Romania.

This study could help the local authorities to realize prioritization lists for rehabilitation work, considering first the historical buildings that are the most important for the local community identity. The cultural value and the history of a city must be well known and promoted.

\section{INTRODUCTION}

Living in cities in seismic areas represent an important aspect of everyday life for many people. Natural disasters are unpredictable, but cities vulnerability and level of exposure can be reduced through prevention policies. Effective protection policies must be strategically planned to be implemented before an earthquake occurs, so the necessity of assessing the vulnerability of a city to know what measures to implement in underlined.

Protection of historical urban areas represent a subject of high interest and actuality, as many cities with historical value are located in seismic areas. Through seismic scenarios and seismic 
vulnerability assessment it is possible to appreciate the possible losses in case of an earthquake and to propose preliminary protection measures.

Nowadays, there are several vulnerability assessment methodologies, but they focus mainly on the structural component and not on the cultural one. To prevent the irrecoverable loss of cultural value, it is important to develop the existing methodologies to they consider also the architectural-artistic values, cultural and socio-economical components. Special attention must be given to the protection of historical cities, as history shown us that many historical cities were changed completely by earthquakes, such as Messina [3], Cusco [4], Lisbon [5], Christchurch [6] and others.

Historical buildings being the most likely to be destroyed in case of an earthquake, is highlighted the opportunity of preparing quick and simplified assessment procedures to help local authorities to obtain prioritization list for rehabilitation work.

The present research paper presents such a methodology that aims to assess the seismic vulnerability of historical buildings in Timisoara, by considering also their cultural value. The entire procedure with detailed analysis was published by I. Onescu in the Ph.D. thesis entitled "Seismic vulnerability assessment of historical centers" [7].

\section{CASE STUDY AREA}

Romania is a country with moderate seismicity, with two important seismic zones. The highest seismicity is registered in Vrancea seismic area, which is located in the center part of the country, while the second most important seismicity is observed in Banat seismic area, in the western part of the The seismicity of the existence of two seis are shallow earthquakes the most probable seismic scenario for the city ground acceleration and macroseismic intensity (Eq.1), illustrating that the expected

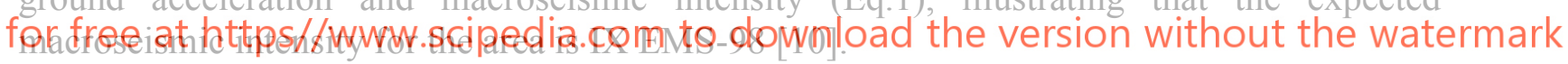

Timisoara city is recognized from 1177, but there are signs that the city existed even before XII ${ }^{\text {th }}$ Century. The city was influenced by several cultures, such as the Ottoman and Habsburgic [11]. The nowadays shape of the city is the results of past influences and more recent interventions, resulting in three historical districts that merged together, forming a cultural promenade that was proposed in the context of Timisoara European Capital of Culture 2023 [7], as shown in Figure 1.

The buildings that represent the case study area are located along the cultural promenade, in a total number of 105, from which 68 are located in Iosefin district and 37 in Fabric historical area, as illustrated in Figure 2 [7]. 


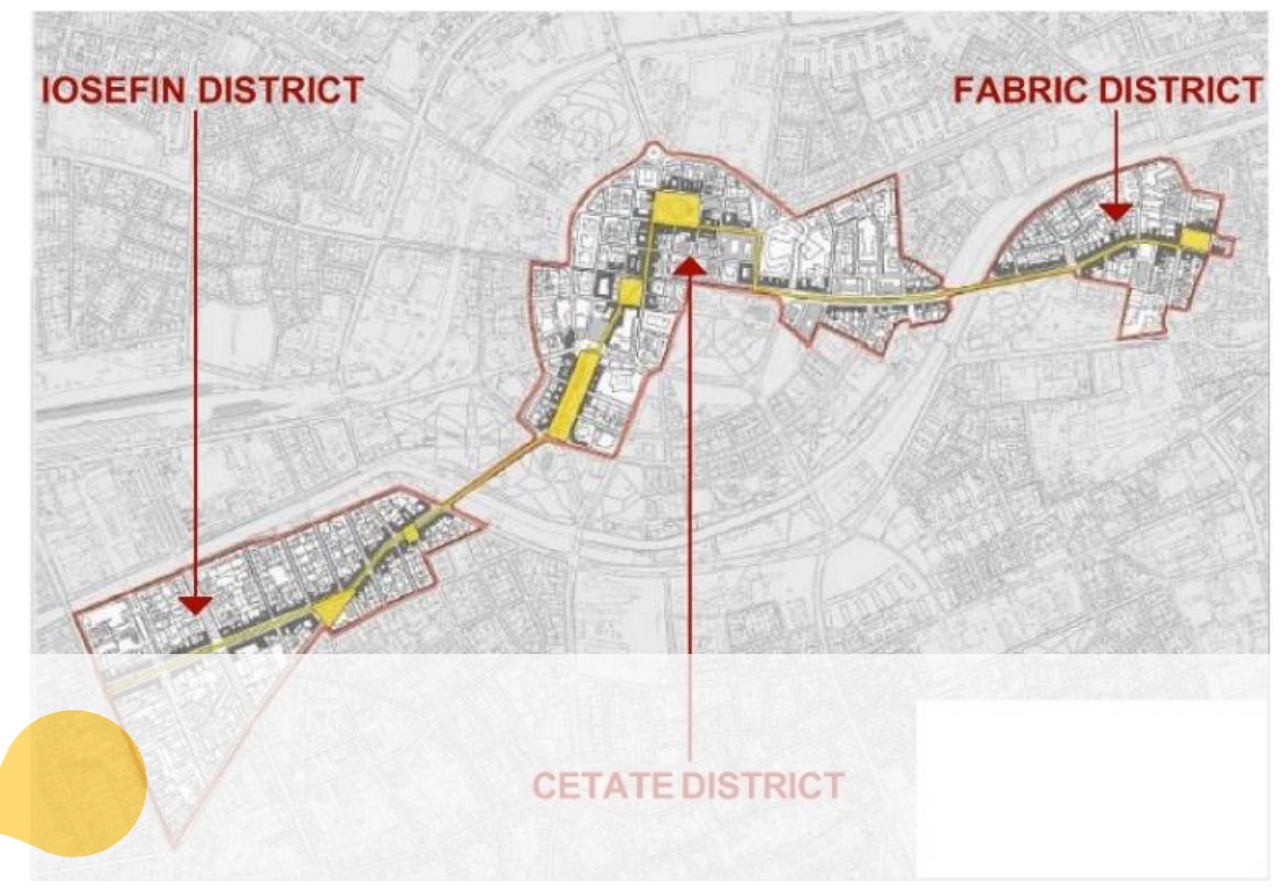

Figure 1. Proposed cultural promenade for Timisoara European Capital of Culture 2021 [7]
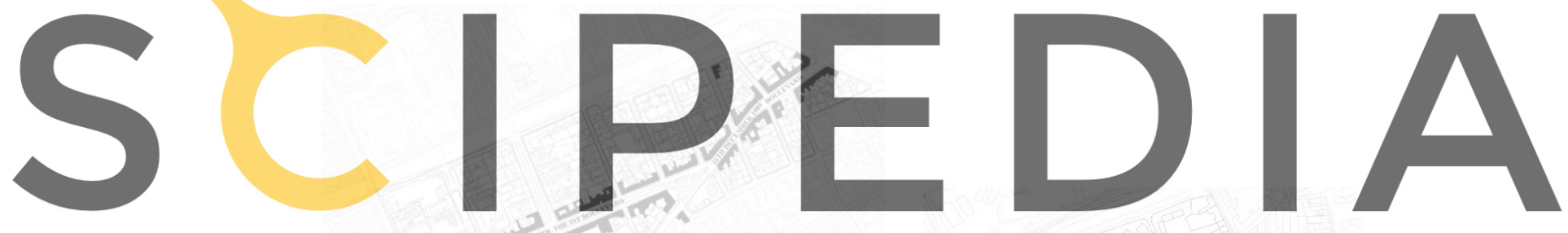

Register for free at https//www.scipedia.com to download the version without the watermark

a)

b)

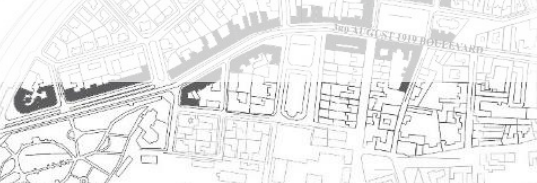

Figure 2. Selected historical buildings for investigation: a) Iosefin district; b) Fabric district; [7]

All the investigated buildings present brick masonry structure of burnt clay brick and lime. Their perimetral walls have $40-80 \mathrm{~cm}$ thicknesses, as well as the medial longitudinal wall, which is also parallel with the main façade. Transversal walls have 10-15 cm thicknesses, with the only role of ensuring the rigidity of the buildings. The aren't usually connected with the façade wall, increasing the risk of activating the out-of-plane failure mechanism in case of an earthquake. At the basement and sometimes at the ground floor, the horizontal structural elements are represented by 15-20 centimeters brick vaults, while at the upper floors there can be found wooden floors. The rigid framework of the roof is usually complex, made after German influences and very high [12]. The main characteristics of the investigated building 
structures are illustrated in Figure 3 [7]. Regarding the height regime, there can be find buildings with basement and ground floor, buildings with basement, ground floor and one top level, respectively buildings with basement, ground floor and two levels above. The total height of the buildings can reach up to 15 meters, as illustrated in Figure 4 [7].

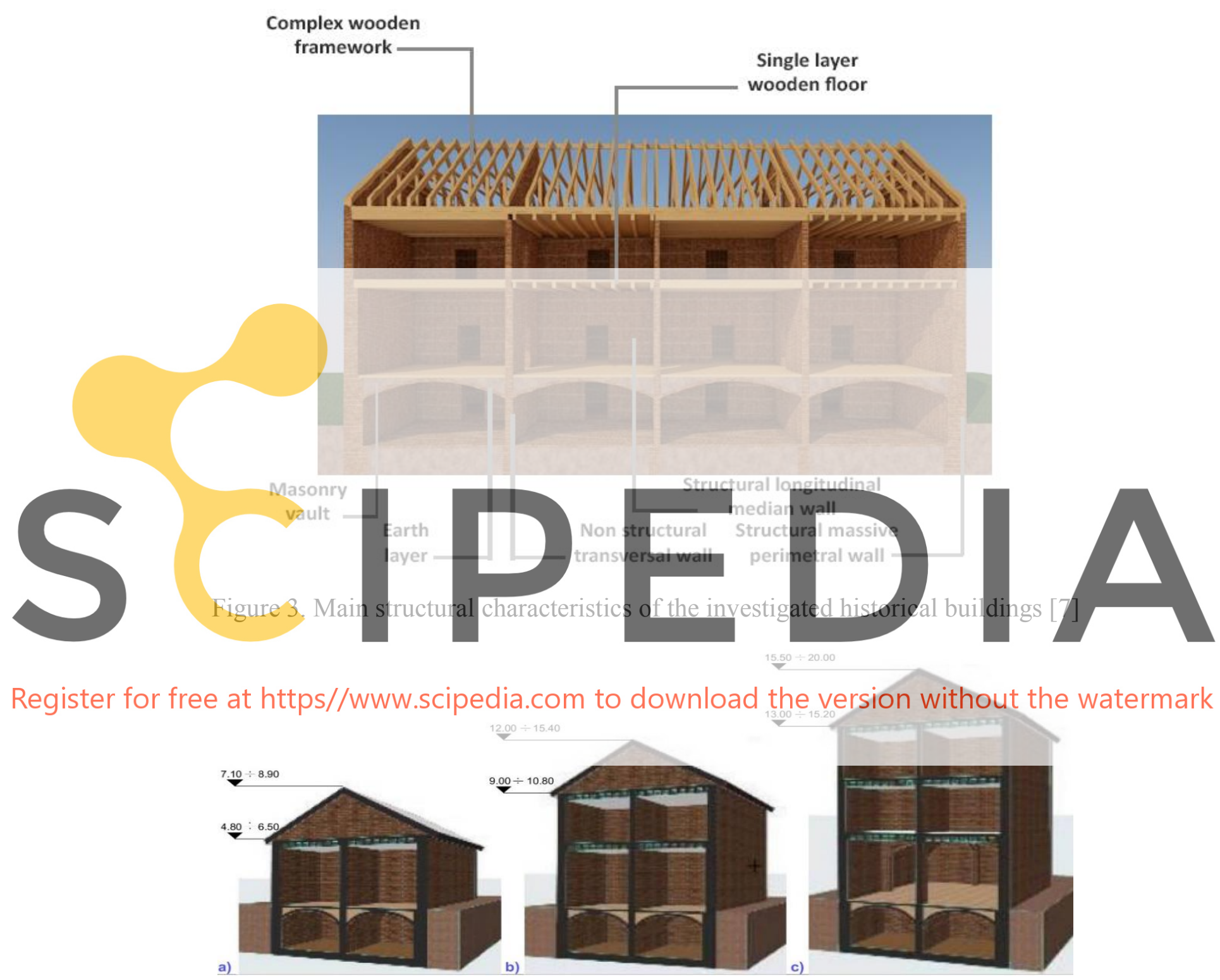

Figure 4. Height of the investigated buildings in dependence of the story number [7]

Buildings in the area are in Eclectic, Art Nouveau and Seccession architectural style. Usually, for the buildings with only ground floor, there can be seen very few architecturalartistic components (Fig. 5a). For buildings with one top level, the decoration level is moderate one, with bosses, decorated balusters and commercial spaces at the ground floor (Fig. 5b). The tallest buildings present also the highest level of architectural-artistic decorative elements, such as frontons, moldings, sculptures with different organic and complex themes (Fig. 5c) [7]. 
a)
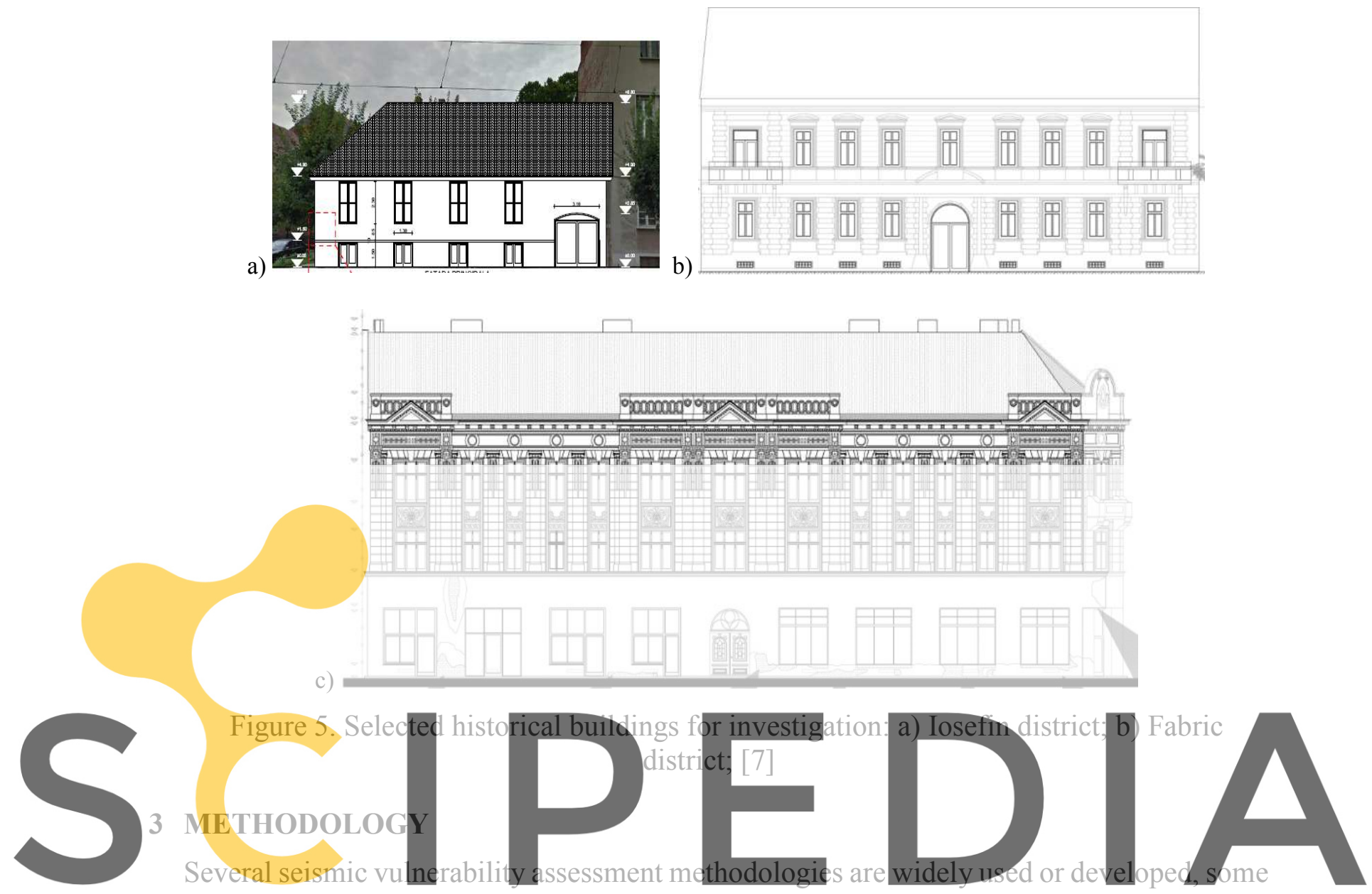

of them with a general character and some of them calibrated to the particularities of a specific

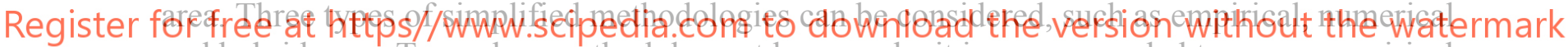
and hybrid ones. To apply a methodology at large scale, it is recommended to use an empirical procedure that was previously calibrated to each urban area by numerical analysis [7].

This is also the case of Timisoara, for which was used the original Vulnerability index method that was proposed at first by Benedetti and Petrini [13] and later on by Formisano and Mazzolani [14]. This original methodology was calibrated for Banat seismic region by Mosoarca and Onescu [15] and was developed even more by Onescu [7] to consider also the cultural value of the buildings.

The final seismic vulnerability assessment methodology is based on a vulnerability form with 42 parameters, for each of them being assigned a score (s). Each parameter can be associated with one vulnerability class, from A (the most favorable) to D (the most dangerous), while the importance of each parameter is underlined by its weight (w).

The 42 parameters are divided into four main categories, such as structural, architecturalartistic, urbanistic and social-economic category. The structural parameters represent the 15 parameters from the original vulnerability form in the original assessment methodology [14]. The architectural-artistic parameters are proposed by Onescu [7] and they refer to the importance and originality of elements such as architectural style, originality, coherency, plastics, artistic assets, decay level, the statute of national monument, existing intervention 
works and others (Fig. 6a). For the urbanistic category, there were considered the context, the importance of the location, the street profile and city silhouette, the presence of the roof and others (Fig. 6b). For the social-economic category, the proposed parameters refer to the importance of the building for the local community, the existence of important social or cultural functions, the representative past events for the building and also the actual economic value [7].

The final proposed vulnerability form is presented in Table 1, while the vulnerability index is represented by the sum of each individual score of the associated vulnerability class multiplied the associated weight (Eq. 2) [7].

a)
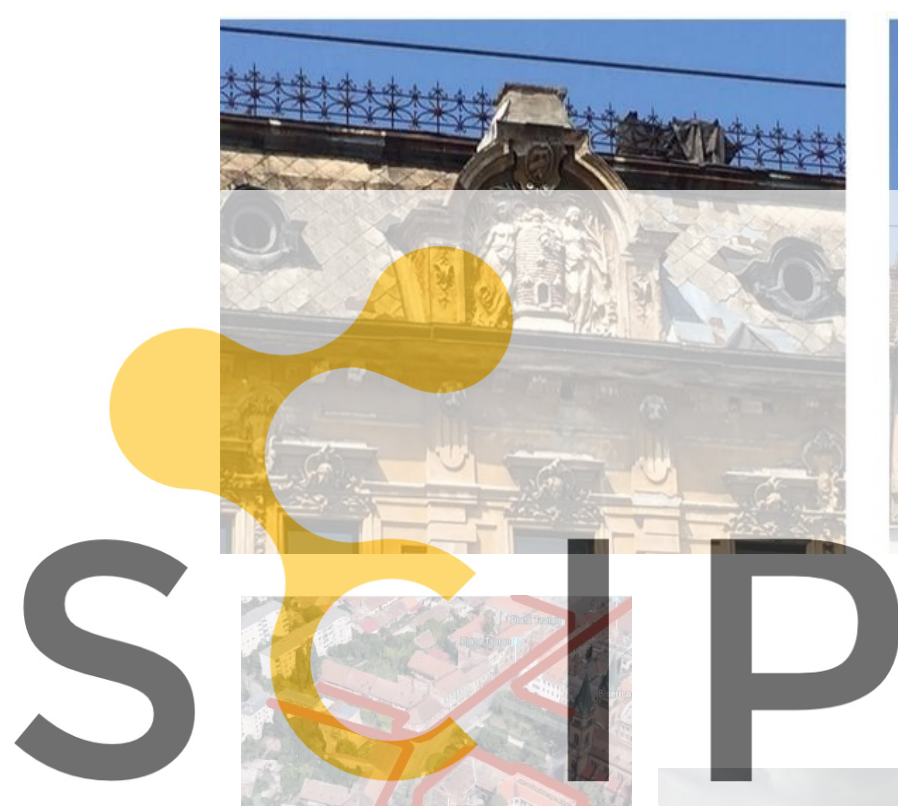
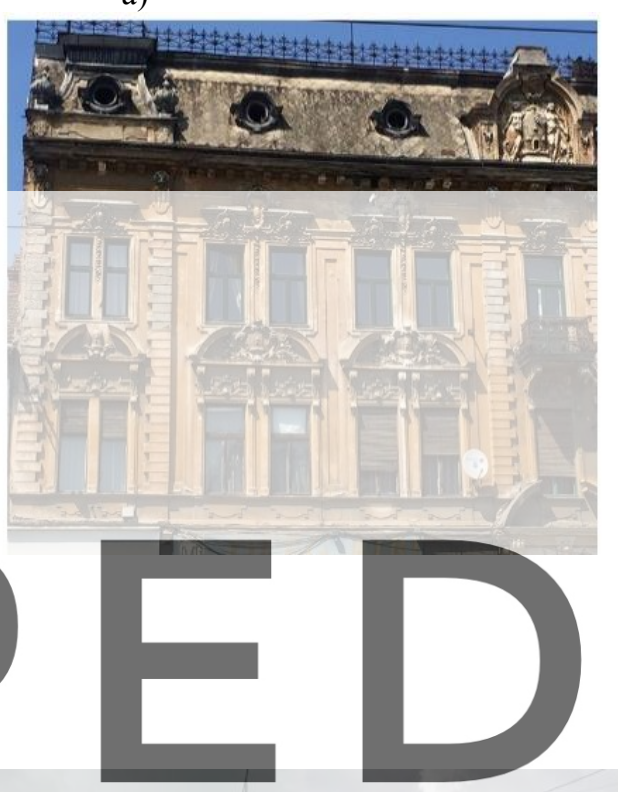
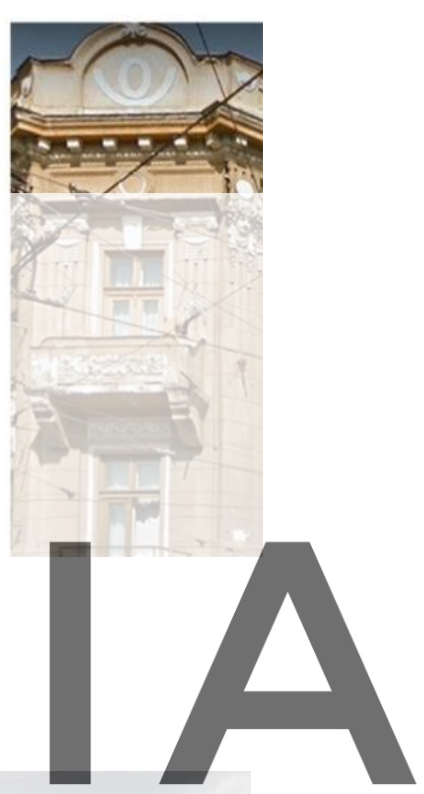

Register for free at https//www.scipedia.com to download the version without the watermark

b)
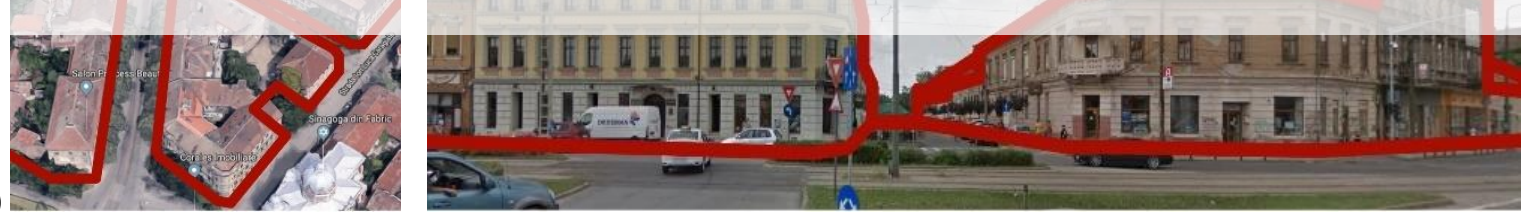

Figure 6. Exemplification of proposed parameters: a) architectural-artistic category; b) urbanistic category; [7]

Table 1. Proposed vulnerability form that considers also the cultural value [7]

\begin{tabular}{|c|c|c|c|c|c|c|c|c|}
\hline \multirow[t]{2}{*}{$\%$} & \multirow[t]{2}{*}{ Criteria } & \multirow[t]{2}{*}{ No. } & \multirow[t]{2}{*}{ Element } & \multicolumn{4}{|c|}{ Class } & \multirow[t]{2}{*}{ Weight } \\
\hline & & & & A & $\mathrm{B}$ & $\mathrm{C}$ & $\mathrm{D}$ & \\
\hline \multirow{7}{*}{$\begin{array}{l}70 \\
\%\end{array}$} & \multirow[t]{7}{*}{ STRUCTURAL } & 1 & Vertical structure organisation & 0 & 5 & 20 & 45 & 1.00 \\
\hline & & 2 & Vertical structure nature & 0 & 5 & 25 & 45 & 0.25 \\
\hline & & 3 & Type of foundation and location/soil & 0 & 5 & 25 & 45 & 0.75 \\
\hline & & 4 & Distribution of structural elements in plan & 0 & 5 & 25 & 45 & 1.50 \\
\hline & & 5 & Regularity in plan & 0 & 5 & 25 & 45 & 0.50 \\
\hline & & 6 & Regularity in elevation & 0 & 5 & 25 & 45 & 1.00 \\
\hline & & 7 & Floor type & 0 & 5 & 15 & 45 & 0.75 \\
\hline
\end{tabular}




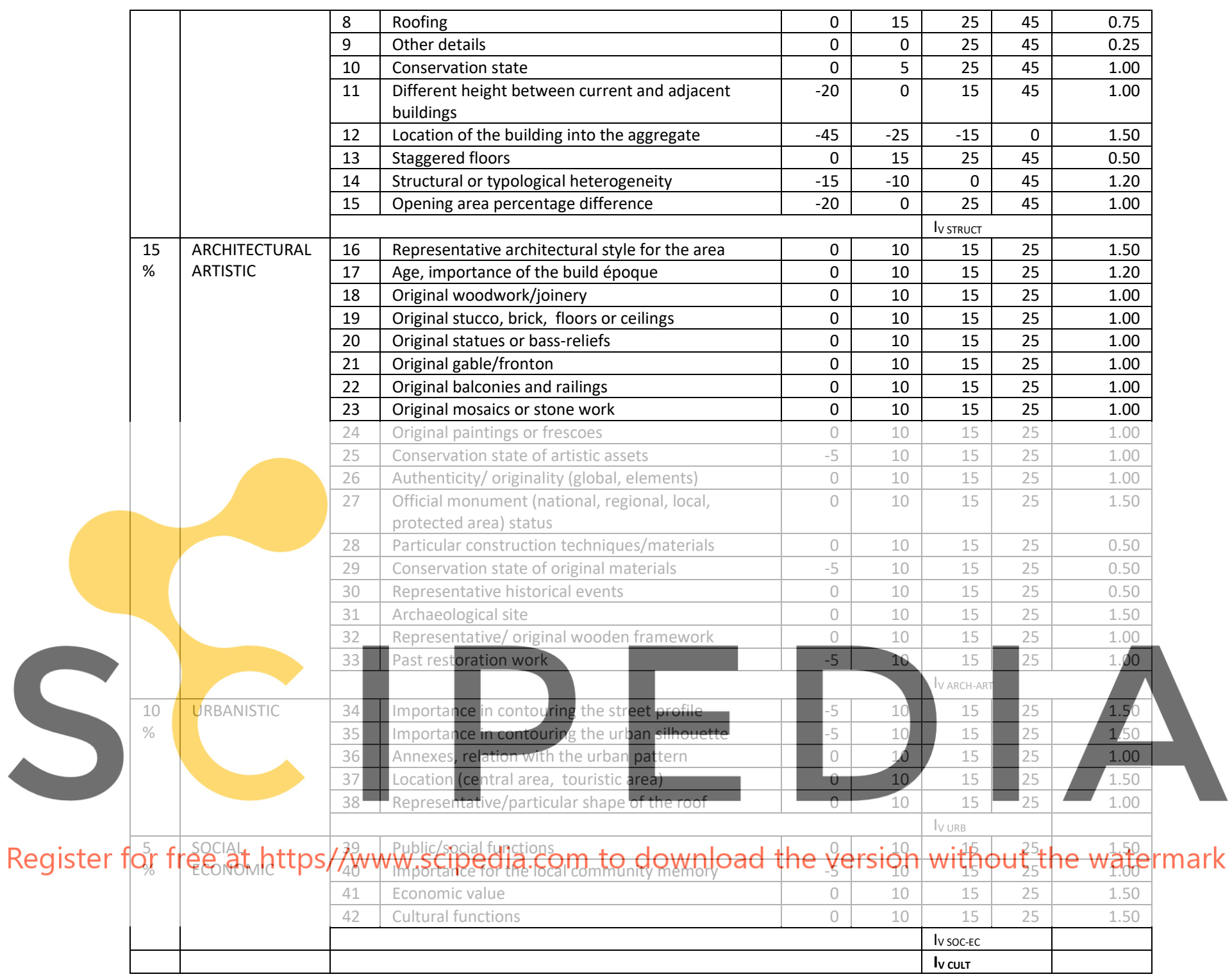

$I_{V C U L T}=0.70 \times \sum_{i=1}^{15} s_{i} \times w_{i}+0.15 \times \sum_{i=16}^{33} s_{i} \times w_{i}+0.10 \times \sum_{i=34}^{38} s_{i} \times w_{i}+0.05 \times \sum_{i=39}^{42} s_{i} \times w_{i}$

Moreover, the proposed methdology considers also the importance of the investigated site, by itnroducing an attenuation factor that can increase the considered cultural vulnerability with up to $50 \%$ for the most important historical sites. The parameters that are considered for the attenuation factor are illustrated in Table 2, while the formula for calculating the actual factor is presented in Equation 3. In the end, the normalized vulnerability index influenced by the cultural value is determined following Equation 4 [7]. 
Table 2. Parameters considered for the attenuation factor [7]

\begin{tabular}{|c|c|c|c|}
\hline \multirow{2}{*}{\multicolumn{2}{|c|}{ Parameter }} & \multirow{3}{*}{$\begin{array}{l}\text { Options } \\
\text { Ancient period (before year } 500 \text { ) }\end{array}$} & \multirow{3}{*}{$\begin{array}{l}\text { Points }\left(\mathrm{p}_{\mathrm{i}}\right) \\
0.30\end{array}$} \\
\hline & & & \\
\hline \multirow[t]{4}{*}{1} & \multirow[t]{4}{*}{ Age of the urban area } & & \\
\hline & & Classical period $(500-1500)$ & 0.25 \\
\hline & & Modern period (1500 - 1945) & 0.22 \\
\hline & & Contemporary period (1945- present) & 0.20 \\
\hline \multirow[t]{4}{*}{2} & \multirow[t]{4}{*}{ Population } & Very high populated (> 1 million inhabitants) & 0.30 \\
\hline & & High populated (<1 million inhabitants) & 0.25 \\
\hline & & Moderate populated (<300000 inhabitants) & 0.22 \\
\hline & & Low populated (<100000 inhabitants) & 0.20 \\
\hline \multirow[t]{4}{*}{3} & \multirow[t]{4}{*}{ Tourism } & Very touristic city & 0.25 \\
\hline & & Touristic city & 0.23 \\
\hline & & Little touristic city & 0.22 \\
\hline & & Not a touristic city & 0.20 \\
\hline \multirow[t]{4}{*}{4} & \multirow{4}{*}{ Worldly recognition } & UNESCO site & 0.35 \\
\hline & & Continental importance & 0.30 \\
\hline & & National importance & 0.25 \\
\hline & & Regional importance & 0.20 \\
\hline \multirow[t]{4}{*}{5} & \multirow[t]{4}{*}{ Conservation state } & Poor & 0.30 \\
\hline & & Moderate & 0.25 \\
\hline & & Good & 0.23 \\
\hline & & Very good & 0.20 \\
\hline
\end{tabular}

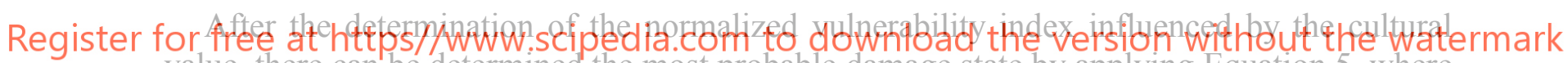
value, there can be determined the most probable damage state by applying Equation 5, where $\Phi$ represents a factor that induces the curve slope and is considered to be 2.3 for residential buildings [16] and I representes the most expected macroseismic intensity for the investigated área, which was previously determined to be IX EMS-98 for Timisoara [7].

$$
\mu_{D}=2.5\left[1+\tanh \left(\frac{I+12.50 \times V_{C U L T}-13.1}{\Phi}\right)\right]
$$

The proposed methodoloy has the main advantage of introducing the cultural component, while being based on a well-known european original empirical procedure.

\section{RESULTS}

The proposed methodology was applied to all 105 historical buildings from the investigated districts in Timisoara, to determine the seismic vulnerability influenced by the cultural value. There were determined the mean vulnerability curves following the standard deviation for the 37 buildings in Fabric area (Fig. 7), for the 68 historical buildings in Iosefin district (Fig. 8), respectively the mean vulnerability for all 105 buildings (Figure 9) [7]. 


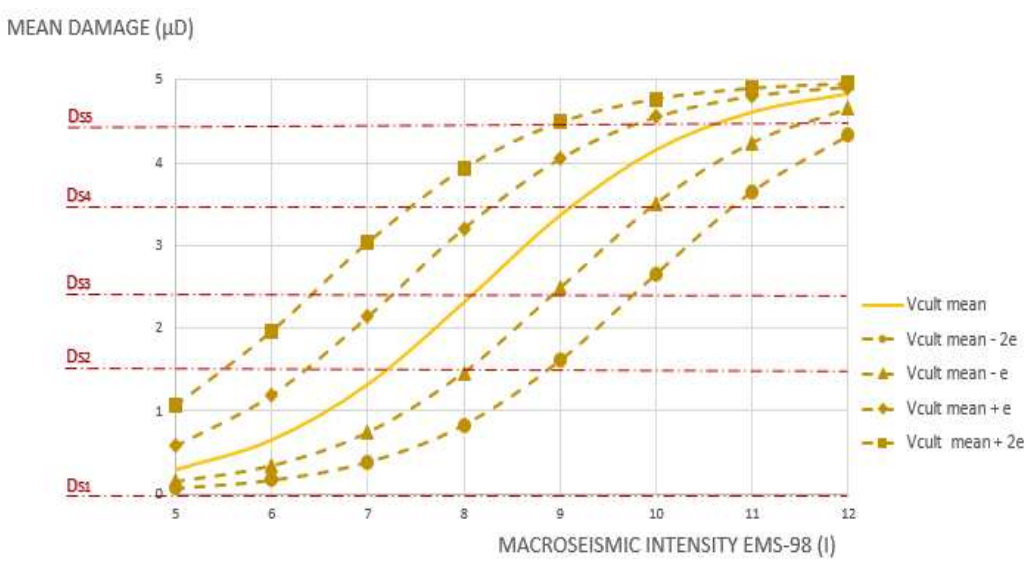

Figure 7. Mean vulnerability curves influenced by the cultural value for buildings in Fabric district; [7]

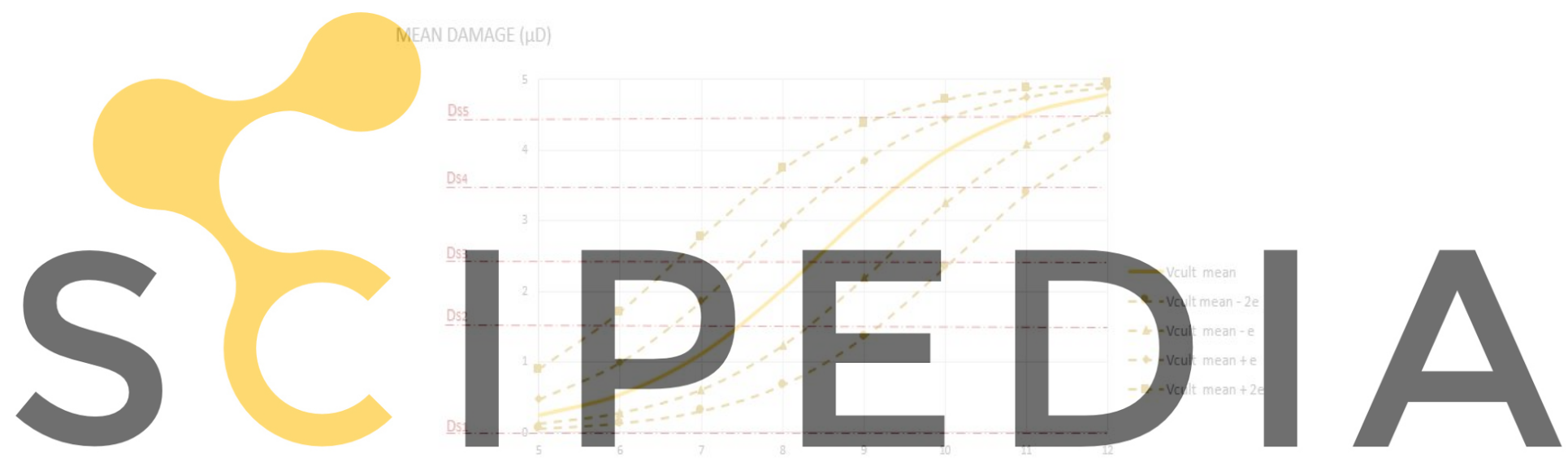

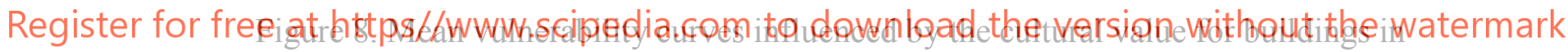
Iosefin historical area [7]

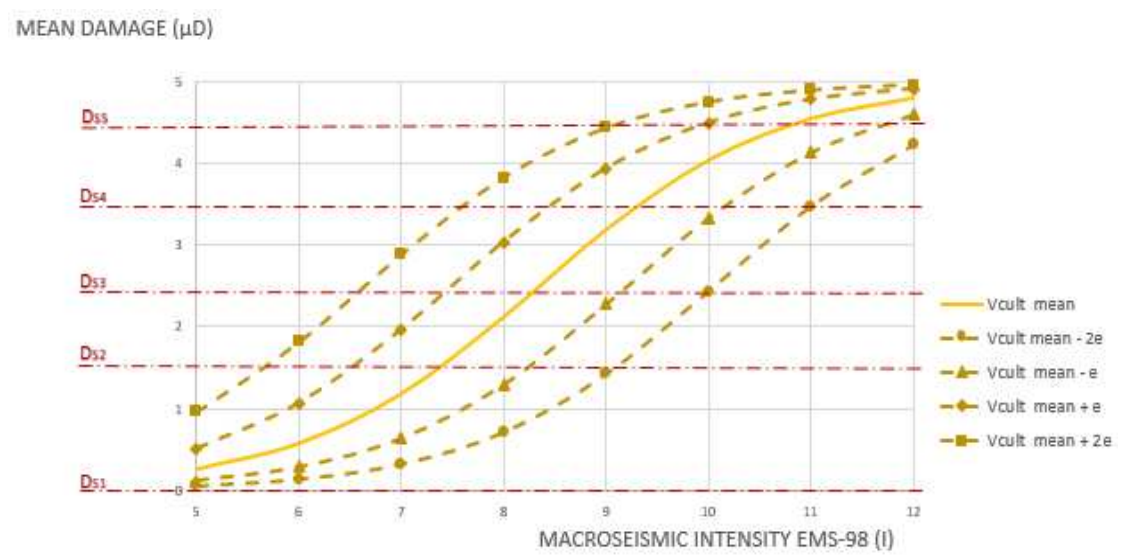

Figure 9. Mean vulnerability curves influenced by the cultural value for all 105 investigated historical buildings [7] 
The results obtained for the investigated historical buildings in Timisoara, for the considered seismic scenario, highlight a medium seismic-cultural vulnerability for the expected macroseismic intensity IX EMS-98. Both Fabric and Iosefin expect a general D3 damage state, with a total range of D1-D4 damage states (Table 3) [7]. Despite the fact that there isn't expected the loss of the bearing capacity of the investigated buildings, the moderate vulnerability is still meaning damages to both structural and non structural elements, leading to the decay of many important artistic assets.

Table 3. Expected damage states for the investigated districts [7]

\begin{tabular}{|l|l|l|l|l|l|}
\hline Historical district & $\begin{array}{l}\text { Damage state } \\
\text { D1 }\end{array}$ & $\begin{array}{l}\text { Damage state } \\
\text { D2 }\end{array}$ & $\begin{array}{l}\text { Damage state } \\
\text { D3 }\end{array}$ & $\begin{array}{l}\text { Damage state } \\
\text { D4 }\end{array}$ & $\begin{array}{l}\text { Damage state } \\
\text { D5 }\end{array}$ \\
\hline losefin & $3.00 \%$ & $25.00 \%$ & $42.50 \%$ & $28.00 \%$ & $1.50 \%$ \\
\hline Fabric & $0.00 \%$ & $16.00 \%$ & $43.50 \%$ & $38.00 \%$ & $2.50 \%$ \\
\hline
\end{tabular}

Following the empirical results, there was designed also the vulnerability maps influenced by the cultural value for both Fabric and Iosefin historical districts, for all the investigated buildings [7], as presented in Figures 10-11.

The seismic vulnerability maps influenced by the cultural value illustrates a $5 \%$ higher level of decay in Fabric area, aspect which is caused by the lack of proper maintenance of historical buildings in the area on one hand and by the increased height of the same building on the other hands.
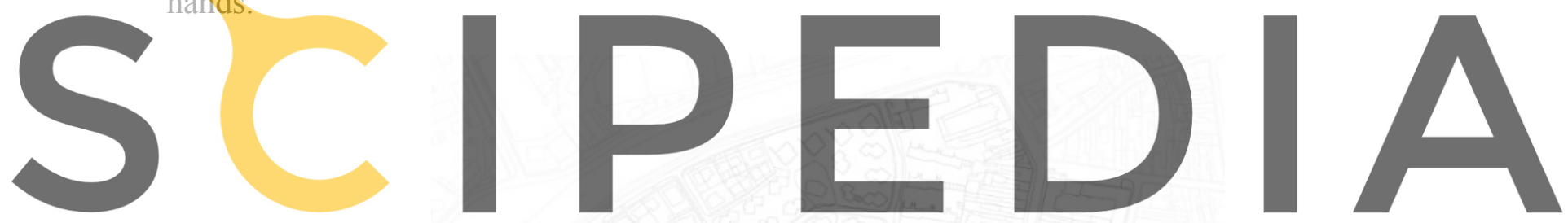

Register for free at https//www.scipedia.com to download the version without the watermark

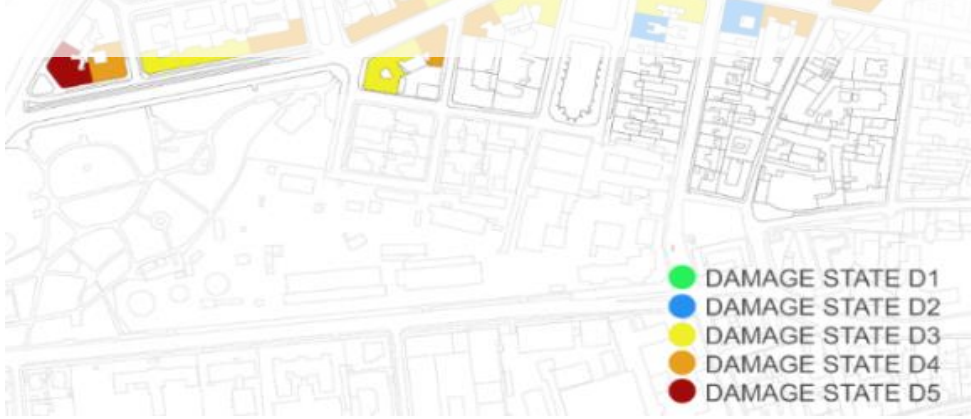

Figure 10. Seismic vulnerability map influenced by the cultural value for Fabric district [7] 


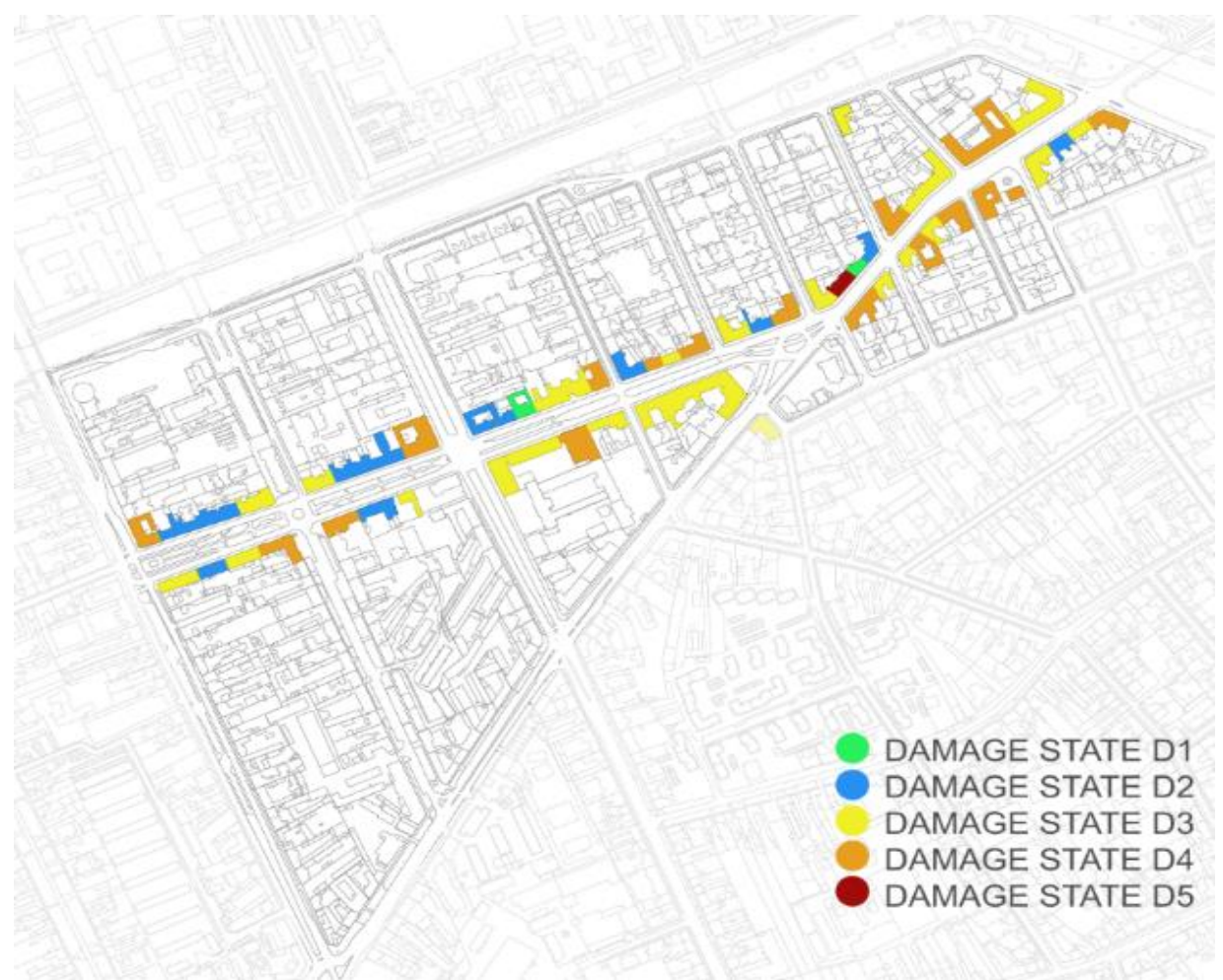

Figure 11. Seismic vulnerability map influenced by the cultural value for Iosefin area [7]

In conclusion, only one building in each district was determined to be in danger of losing its bearing capacity in case of an earthquake with IX EMS-98 macroseismic intensity. In general, the most vulnerable buildings are the one located on corner position within the aggregate.

\section{CONCLUSIONS}

The proposed seismic vulnerability assessment influenced by the cultural value represent a useful tool for the local authorities to obtain in a quick and simplified way a prioritization list for rehabilitation work in the historical districts of the city.

The main advantage of the proposed procedure is the fact that is suitable for territorial scale application, with minimum resources in terms of time, human resources and finances.

The presented multidisciplinary methodology can be easily applied to any other historical city in similar seismic area with Banat one, while it can also be easily adapted for any other site.

It brings a plus of knowledge in the field of seismic vulnerability assessment, while harmoniously intertwining the field of civil engineering with that of architecture.

Least but not last, the proposed procedure aims to protect historical cities against earthquakes, by allowing a simplified assessment of their vulnerabilities, while considering also the cultural values of the area.

The results presented in this paper indicate the fact that the city of Timisoasa, which was elected European Capital of Culture 2023, has a moderate seismic vulnerability influenced by the cultural value, with more buildings that will need rehabilitation work in Fabric historical district. 


\section{REFERENCES}

[1] M. Mosoarca, I. Onescu, E. Onescu, B. Azap, N. Chieffo, M. Szitar-Sirbu, Seismic vulnerability assessment for the historical areas of the Timisoara city, Romania, Eng. Fail. Anal. 101 (2019) 86112. doi:10.1016/J.ENGFAILANAL.2019.03.013.

[2] A. Formisano, F. Mazzolani, G. Florio, R. Landolfo, A quick methodology for seismic vulnerability assessement of historical masonry aggregates, COST Action C26 Urban Habitat Constr. under Catastrophic Events. (2010). doi:10.13140/2.1.1706.3686.

[3] S. Chen, Hazard Mitigation for Earthquake and Subsequent Fire, ANCER Annual Meeting: Networking of Young Earthquake Engineering Researchers and Professionals (2004).

[4] G. E. Ericksen, J. F. Concha, and E. Silgado, The Cusco, Peru, Earthquake of May 21, 1950, Bulletin of the Seismological Society of America (1954), vol. 44, no. 2A, pp. 97-112.

[5] A. S. Pereira, The opportunity of a disaster: The economic impact of the 1755 Lisbon earthquake, Journal of Economic History (2009), vol. 69, no. 2, pp. 466-499.

[6] A. Kaiser et al., The Mw 6.2 Christchurch earthquake of February 2011: Preliminary report, New Zealand Journal of Geology and Geophysics (2012), vol. 55, no. 1, pp. 67-90.

[7] I. Onescu, Seismic vulnerability assessment of historical urban centers, Ph.D. thesis (2020).

[8] A. Bala and V. Raileanu, Crustal seismicity and active fault systems in Romania, International Multidisciplinary Scientific GeoConference Surveying Geology and Mining Ecology Management (2015), SGEM, vol. 3, no. 1, pp. 799-806.

[9] E. Oros, Macroseismic and instrumental seismicity of the Banat Region and its significance on the local seismic hazard and risk, in Proc. and CD-Rom of the "Thirty Years from the Romania Earthquake of March 4, 1977” Symposium (2007).

[10] M. Kostov, Site specific estimation of cumulative absolute velocity, in 18th International Conference on Structural Mechanics in Reactor Technology (SMiRT 18) (2005), Beijing, China.

[11] M. Opris, Timisoara - small urbanistic monography, In Romanian. Bucuresti: Editura Tehnica (1987).

[12] M. Mosoarca, I. Onescu, E. Onescu, B. Azap, N. Chieffo, and M. Szitar-Sirbu, Seismic vulnerability assessment for the historical areas of the Timisoara city, Romania, Engineering Failure Analysis (2019), vol. 101, pp. 86-112.

[13] D. Benedetti and V. Petrini, On the seismic vulnerability of masonry buildings: an evaluation method (in Italian), L'Industria delle Costruzioni (1984), vol. 149, pp. 66-74.

[14] A. Formisano, R. Landolfo, F. Mazzolani, and G. Florio, A quick methodology for seismic vulnerability assessement of historical masonry aggregates, COST Action C26: Urban Habitat Constructions under Catastrophic Events (2010), no. September.

[15] Mosoarca M., Onescu I., Onescu E., Anastasiadis A., Seismic vulnerability assessment methodology for historical masonry buildings in the near-field areas, Engineering Failure Analysis (2020), Vol. 115.

[16] R. Vicente, S. Parodi, S. Lagomarsino, H. Varum, J. A. R. Mendes, and D. Silva, Seismic vulnerability assessment, damage scenarios and loss estimation. Case study of the old city centre of Coimbra, Portugal, in Proceedings of the 14th World Conference on Earthquake Engineering (2008). 